\title{
FTO gene-lifestyle interactions on serum adiponectin concentrations and central obesity in a Turkish population
}

Article

Accepted Version

Isgin-Atici, K., Alsulami, S., Turan-Demirci, B., Surendran, S., Sendur, S. N., Lay, I., Karabulut, E., Ellahi, B., Lovegrove, J. A., Alikasifoglu, M., Erbas, T., Vimaleswaran, K. S. and Buyuktuncer, Z. (2021) FTO gene-lifestyle interactions on serum adiponectin concentrations and central obesity in a Turkish population. International Journal of Food Sciences and Nutrition, 72 (1). pp. 375-385. ISSN 1465-3478 doi: https://doi.org/10.1080/09637486.2020.1802580 Available at https://centaur.reading.ac.uk/91931/

It is advisable to refer to the publisher's version if you intend to cite from the work. See Guidance on citing.

To link to this article DOI: http://dx.doi.org/10.1080/09637486.2020.1802580

Publisher: Informa Healthcare

All outputs in CentAUR are protected by Intellectual Property Rights law, including copyright law. Copyright and IPR is retained by the creators or other copyright holders. Terms and conditions for use of this material are defined in the End User Agreement. 


\section{www.reading.ac.uk/centaur}

\section{CentAUR}

Central Archive at the University of Reading

Reading's research outputs online 
$1 \quad F T O$ gene-lifestyle interactions on serum adiponectin concentrations and

2 central obesity in a Turkish population

3 Kubra Isgin-Atici ${ }^{1, \#}$, Sooad Alsulami ${ }^{2,3 \#}$, Busra Turan-Demirci ${ }^{1}$, Shelini

4 Surendran $^{2}$, Suleyman Nahit Sendur ${ }^{4}$, Incilay Lay ${ }^{5}$, Erdem Karabulut ${ }^{6}$, Basma

5 Ellahi $^{7}$, Julie A. Lovegrove ${ }^{2}$, Mehmet Alikasifoglu ${ }^{8}$, Tomris Erbas ${ }^{4}$,

6 Vimaleswaran Karani Santhanakrishnan ${ }^{2, \#, *}$ and Zehra Buyuktuncer ${ }^{1, \#, *}$

$7 \quad{ }^{1}$ Department of Nutrition and Dietetics, Faculty of Health Sciences, Hacettepe University,

8 Ankara, Turkey

$9 \quad{ }^{2}$ Department of Food and Nutritional Sciences, University of Reading, PO Box 226,

10 Whiteknights, Reading RG6 6AP, UK

$11{ }^{3}$ Department of Clinical Nutrition, Faculty of Applied Medical Sciences, King Abdulaziz

12 University, Jeddah, Saudi Arabia

$13{ }^{4}$ Department of Endocrinology and Metabolism, School of Medicine, Hacettepe University,

14 Ankara, Turkey

$15{ }^{5}$ Department of Medical Biochemistry, Faculty of Medicine, Hacettepe University, Ankara,

16 Turkey; Clinical Pathology Laboratory, Hacettepe University Hospitals, Ankara, Turkey

$17{ }^{6}$ Department of Biostatistics, Faculty of Medicine; Department of Bioinformatics Hacettepe

18 University, Ankara, Turkey

$19{ }^{7}$ Faculty of Health and Social Care, University of Chester, Chester CH1 4DS, UK

$20{ }^{8}$ Department of Medical Genetics, School of Medicine, Hacettepe University Ankara,

21 Turkey; Genetics Diagnostic Centre, DAMAGEN, Ankara, Turkey 
26 Hacettepe University, Faculty of Health Sciences, Department of Nutrition and Dietetics,

27 06230, Ankara, Turkey.

28 Tel: +90-3123051094.

29 Fax: +90-3123091310

30 E-mail: zbtuncer@hacettepe.edu.tr

31

32 Vimaleswaran Karani Santhanakrishnan

33 Department of Food and Nutritional Sciences, University of Reading, PO Box 226,

34 Whiteknights, Reading RG6 6AP, UK.

35 Tel: +44 -0118 -378 -8702

36 Fax: +44(0) 1189314404

37 E-mail: v.karani@reading.ac.uk.

39 \#:These authors contributed equally to the this work.

40

41 


\section{FTO gene-lifestyle interactions on serum adiponectin concentrations and central obesity in a Turkish population}

The aim of the study was to investigate whether lifestyle factors modify the association fat mass and obesity-associated (FTO) gene single nucleotide polymorphisms (SNPs) and obesity in a Turkish population. The study included 400 unrelated individuals, aged 24-50 years recruited in a hospital setting. Dietary intake and physical activity were assessed using 24-hour dietary recall and self-report questionnaire, respectively. A genetic risk score (GRS) was developed using FTO SNPs, rs9939609 and rs10163409. Body mass index and fat mass index were significantly associated with FTO SNP rs9939609 ( $\mathrm{P}=0.001$ and $\mathrm{P}=0.002$, respectively) and GRS ( $\mathrm{P}=0.002$ and $\mathrm{P}=0.003$, respectively). The interactions between SNP rs9939609 and physical activity on adiponectin concentrations, and SNP rs10163409 and dietary protein intake on increased waist circumference were statistically significant ( $\mathrm{P}_{\text {interaction }}=0.027$ and $\mathrm{P}_{\text {interaction }}=0.044$, respectively). This study demonstrated that the association between FTO SNPs and central obesity might be modified by lifestyle factors in this Turkish population.

Keywords: FTO gene variant; obesity; gene-diet interaction; adiponectin; genetic risk score; physical activity

\section{Introduction}

Obesity has been recognised as a worldwide public health problem due to its rising prevalence and concomitant health problems. The prevalence of overweight and obesity in Turkey were reported as $64.4 \%$ and $28.8 \%$, respectively by WHO (WHO, 2018). Obesity can lead to other chronic diseases including type 2 diabetes (T2D), cardiovascular diseases

(CVD), hypertension, cancer and osteoarthritis (Forse et al. 2020). A combination of 
interactions between genetic and environmental factors is required for the development of a complex disease such as obesity (Franks and McCarthy 2016; Milagro et al. 2020). Studies have identified approximately 140 genes to be associated with obesity, and the fat mass and obesity associated (FTO) gene has been reported to be the strongest susceptibility gene for human obesity (Pigeyre et al. 2016).

The FTO gene is located on chromosome 16q12.2 and codes for a protein with 2oxoglutarate dependent nucleic acid demethylase activity which is involved in DNA repair and the accumulation of fat in the body (Clifton et al. 2006; Chen and Du 2019). FTO is highly expressed in the brain, including the hypothalamus, adipocytes, pancreatic islet cells, and adrenal glands (Frayling et al. 2007). FTO gene has been suggested to control energy homeostasis and food intake (Abete et al. 2020). Previous studies have shown that, of the various obesity susceptibility genes, single-nucleotide polymorphisms (SNPs) located in the first intron of FTO gene has provided the strongest evidence for genetic predisposition to obesity (Frayling et al. 2007; Scuteri et al. 2007; Speliotes et al. 2010; Loos and Yeo 2014; Babenko et al. 2019; Fonseca et al. 2020). The minor allele 'A' of the FTO SNP rs9939609 has been consistently associated with higher BMI in various populations (Frayling et al. 2007; Hertel et al. 2011; Peng et al. 2011; Corella et al. 2012; Li et al. 2012; Qi et al. 2014; Wang et al., 2020; Schlauch et al. 2020). Furthermore, a meta-analysis reported that the association between the SNP rs9939609 and BMI was replicated in 13 cohorts with 38,759 participants, where individuals with the 'AA' genotype had 1.67-time higher odds of obesity than those with the 'TT' genotype (Frayling et al. 2007). In the Turkish population, the risk alleles of the FTO rs1421085 and rs9939609 polymorphisms were shown to have significant 
associations with the risk of obesity in women and metabolic syndrome (MetS) in men (Guclu-Geyik et al. 2016).

Turkish adults are characterized with low levels of total and high-density lipoprotein cholesterol, and high risk of CVD, that distinguish them from Europeans (Onat 2001). They also have increased susceptibility to impaired glucose tolerance and MetS primarily driven by obesity (Onat and Can 2014). Among the non-communicable diseases (NCDs) that accounted for $88.0 \%$ of deaths in Turkey, CVD has shown to contribute to $47.73 \%$ of overall deaths (WHO, 2018). Targeting modifiable risk factors for NCDs including obesity could prevent many deaths. Therefore, several health promotion campaigns such as "Reducing Portion Sizes" and "Move for Health" have been implemented for the prevention of obesity in Turkey (WHO, 2016; OECD, 2017). However, obesity is a multifactorial disorder, and identifying gene-environment interactions are needed to understand the aetiology and pathophysiology of obesity and also to develop more effective personalised preventative strategies (Castillo et al. 2017; Dahlman and Ryden 2020). To date, several FTO-dietary intake interactions on obesity-related outcomes have been examined in different populations (Grau et al. 2009; Sonestedt et al. 2009; Lappalainen et al. 2012; Ortega-Azorin et al. 2012; Phillips et al. 2012; Vimaleswaran et al. 2012; Qi et al. 2014; Merritt et al. 2018; Saber-Ayad et al. 2019) however, there are no such studies to date in a Turkish population The investigations of the gene-diet interactions in different ethnic groups are crucial to develop personalised nutrition strategies for each ethnic group due to the genetic heterogeneity (Vimaleswaran 2017). The FTO SNP rs9939609 has been associated with several dietary components including dietary protein intake (Lappalainen et al. 2012; Qi et al. 2014; Merritt 
111 et al. 2018) and the SNP rs10163409 in FTO was among the top associations in a large

112 genome-wide meta-analysis study (GWAS) for total caloric intake (Chu et al. 2013).

113 Therefore, this study aimed to assess whether FTO variants, rs9939609 and rs10163409, are

114 associated with obesity in 400 Turkish individuals and to determine whether these SNPs

115 interact with dietary intake and physical activity on obesity outcomes.

116 Materials and Methods

117 Study population

118 A total of 400 unrelated individuals, aged 24-50 years, were recruited from the outpatient

119 clinic of Department of Endocrinology and Metabolism at the Hacettepe University

120 Hospitals, Ankara, Turkey. This study was conducted as part of the GeNuIne Collaboration

121 that investigates the interactions between genetic and dietary factors on metabolic diseases

122 in different ethnic groups (Vimaleswaran 2017). The study participants were screened based

123 on the following inclusion criteria: 1) routine visits to the outpatient clinic, 2) aged 18-50

124 years, and 3) having a BMI $\geq 18.50 \mathrm{~kg} / \mathrm{m}^{2}$. The exclusion criteria were: 1) having specific

125 health problems including, liver and kidney diseases, mental and psychological disorders,

126 history of cancer, and serious endocrine disorders (hypothyroidism, hyperthyroidism or

127 hypopituitarism), 2) history of bariatric surgery, 3) being pregnant or lactating, 4) using drugs

128 that affect body weight. Researchers informed and invited the eligible participants for their

129 participation in to the study. The study was approved by the local ethics committee of

130 Hacettepe University (GO 15/612-11), and all the participants provided the signed written

131 consent.

132 Study design

133 A cross-sectional case-control study design was used, where participants were divided into

134 two groups: obese (BMI $\left.\geq 25.00 \mathrm{~kg} / \mathrm{m}^{2}, \mathrm{n}=200\right)$ and non-obese (BMI= 18.50-24.99 $\mathrm{kg} / \mathrm{m}^{2}$,

$135 \mathrm{n}=200$ ). All participants underwent a physical examination by the research endocrinologists, 
136 followed by clinical, biochemical and lifestyle assessments, and genetic analysis of FTO

$137 \quad$ SNPs rs9939609 and rs10163409.

\section{Anthropometrical Measurements}

139 Body weight and height were measured by standard methods using a calibrated digital scale

140 (Seca 220 Scale, Germany). BMI calculation was based on the body weight (in kilograms)

141 divided by the square of height (in meter) (WHO, 2020). BMI classification of the WHO was

142 used to classify the individuals as non-obese (BMI $<25.00 \mathrm{~kg} / \mathrm{m}^{2}$ ) and obese (BMI $\geq 25.00$

$143 \mathrm{~kg} / \mathrm{m}^{2}$ ) (WHO, 2005). The waist circumference (WC) was measured by a standard method

144 (WHO, 2011). Increased WC (central obesity) was defined based on cut-points established

145 for Turkish adults (WC $\geq 90 \mathrm{~cm}$ for $\mathrm{men} / \geq 80 \mathrm{~cm}$ for women) (Sonmez et al. 2013). Body

146 composition was analysed by bioelectrical impedance using the Tanita MC-980 MA Multi

147 Frequency Segmental Body Composition Analyzer (USA). Fat mass index (FMI) was

148 calculated based on the fat mass (in kilograms) divided by the square of height (in meter)

149 (Peltz et al. 2010). All anthropometrical measurements were taken by the research dieticians.

\section{$150 \quad$ Biochemical and clinical measures}

151 Serum adiponectin was analysed by ELISA kits (Ebioscience, Austria) at Hacettepe

152 University Hospitals, Clinical Pathology Laboratory. The physical examination included the

153 measurement of systolic (SBP) and diastolic blood pressure (DBP) using a stethoscope and

154 sphygmomanometer in the right arm of the participants after sitting in a comfortable position

155 in a quiet room for at least $15 \mathrm{~min}$. Both blood pressures were measured twice at 5-minute intervals and recorded on average (Frese et al. 2011). 
158 Dietary intake was assessed using 24-hour dietary recall method that was carried out by trained research dieticians. A photographic atlas of food portion sizes and common household measures were used to facilitate the quantification of the amount of food consumed. Total

161 energy, macro- and micronutrient intakes of participants were analysed from the records using BeBIS software (BeBIS, Nutrition Information System, Version 8).

\section{Other lifestyle factors}

164 The socio-demographic characteristics, family and medical history, smoking and alcohol consumption were recorded. The physical activity level was assessed using the Turkish version of the International Physical Activity Questionnaire (IPAQ) (Saglam et al. 2010).

\section{SNPs selection and genotyping}

168 FTO gene was selected based on its consistent and strong associations with obesity traits in

169 large-scale GWASs (Frayling et al. 2007). The SNP rs9939609 is the most commonly studied

170 variant and consistently associated with obesity phenotypes across multiple ethnicities

171 (Frayling et al. 2007; Hertel et al. 2011; Peng et al. 2011; Corella et al. 2012; Li et al. 2012;

172 Loos and Yeo 2014; Qi et al. 2014) and SNP rs10163409 has been shown to be associated

173 with dietary energy intake from macronutrients (Chu et al. 2013). Therefore, FTO SNPs,

174 rs9939609 and rs10163409, which have been shown to be associated with obesity traits and

175 dietary intake in large GWASs, were genotyped. The genotype frequencies of the FTO SNPs, rs9939609 and rs10163409, were in Hardy Weinberg equilibrium (p>0.05). 
178 by the salting out method. Genotyping of the SNPs, rs9939609 and rs10163409, were

179 performed using KASP assay (a competitive allele-specific polymerase chain reaction that

180 incorporates a fluorescent resonance energy transfer quencher cassette), and the KASP

181 primers were designed using Kraken software system (LGC, https://www.lgcgroup.com).

182 Genotyping assays were carried out according to the manufacturer's instructions with a 7500

183 Real time PCR System (Applied Biosystems). The following thermal cycling profile were

184 used: $15 \mathrm{~min}$ at $94^{\circ} \mathrm{C} ; 10$ cycles of $20 \mathrm{~s}$ at $94^{\circ} \mathrm{C}, 60 \mathrm{~s}$ at $61^{\circ} \mathrm{C}$ with decrement $-0.6^{\circ} \mathrm{C} /$ per

185 cycle and 26 cycles of $20 \mathrm{~s}$ at $94^{\circ} \mathrm{C}, 60 \mathrm{~s}$ at $55^{\circ} \mathrm{C} ; 60 \mathrm{~s}$ at $37^{\circ} \mathrm{C}$.

\section{Statistical analysis} model was used, where common homozygous genotypes were compared to combined rare homozygous and heterozygous genotypes. A genetic risk score (GRS) was created from both the FTO SNPs where the presence of one risk allele of any of the variants was scored as one point. This GRS ranged from 0 (homozygous individuals for non-risk alleles) to 4 points

SPSS software (version 23.0) was used for statistical analysis. The Hardy-Weinberg equilibrium was assessed using the $\mathrm{x}^{2}$ goodness-of-fit test. Genotype frequencies and distribution in groups were compared using Pearson's chi-squared test. Continuous variables are presented as means and standard deviations (SD), and groups were compared using the independent t-test.

As the number of individuals with rare homozygous genotypes was low, a dominant (homozygous individuals for the risk alleles of both FTO polymorphisms). The GRS variable 
was then categorised into two groups based on the number of points; 1st group: individuals with scores of $<2$ points; 2 nd group: individuals with scores of $\geq 2$ points.

The independent and joint effects of FTO SNPs on the risk of obesity were assessed using the odds ratios (ORs) and 95\% confidence intervals (CIs) that were calculated by logistic regression models. Also, the associations between FTO polymorphisms (separately and joint) and the continuous outcomes were tested using general linear models. Models were adjusted for age, gender, hypertension, CVD and obesity status wherever appropriate. Furthermore, FTO gene-environment interactions on continuous and categorical outcomes were tested using linear and logistic regression models, respectively. Interactions were investigated by including the interaction terms (e.g.,carbohydrate*genotype) in the regression models. Environmental factors that were investigated included dietary intake (carbohydrate, protein, fibre and fat intakes in grams/day) and physical activity. Furthermore, statistically significant interactions were investigated in more depth, where individuals were stratified by the tertiles of the lifestyle factor.

\section{Results}

\section{Characteristics of the Participants}

Obese individuals were older, and had higher BMI, WC and FMI and lower adiponectin levels than the controls $(\mathrm{P}<0.001$, for each). The cases and controls were not statistically different in terms of their food intake and physical activity levels $(\mathrm{P}>0.05)$ (Table 1).

\section{Associations between FTO variants and obesity-related traits}

Genotype distributions and minor allele frequencies (MAFs) for both SNPs are shown in Table 2. The MAFs of the SNPs, rs 10163409 and rs9939609, were $\mathrm{T}=0.37$ and $\mathrm{A}=0.39$, 
respectively. The associations between SNP rs9939609 and BMI (P=0.001) and FMI

$221(\mathrm{P}=0.002)$ were found significant where the 'A' (AT/AA) allele carriers had significantly

222 higher BMI and FMI than 'TT' homozygotes (Table 3). Furthermore, 'A' allele carriers had

223 significantly higher $\mathrm{WC}(\mathrm{P}=0.007)$ and lower adiponectin levels $(\mathrm{P}=0.031)$ compared to non-

224 carriers. The FTO SNP rs10163409 did not show any significant association with obesity

225 traits (Table 3).

226 Interactions between FTO variants and dietary intake on obesity-related traits

227 FTO gene-dietary protein intake interactions

228 The significant interactions between SNP rs10163409 and protein intake on the risk of 229 increased $\mathrm{WC}\left(\mathrm{P}_{\text {interaction }}=0.044\right)$ and $\mathrm{WC}$ as a continuous variable $\left(\mathrm{P}_{\text {interaction }}=0.007\right)$ were 230 observed. Stratification of the dietary protein intake into tertiles showed that, in the highest 231 tertile group with a mean $\pm \mathrm{SD}$ of $138 \pm 38 \mathrm{~g}$ /day protein intake, ' $\mathrm{T}$ ' allele carriers of the $\mathrm{SNP}$ 232 rs10163409 had a significantly higher risk of central obesity [OR=3.3 (95\% CI: 1.149233 9.478), $\mathrm{P}=0.027$ ] than those with 'AA' genotype (Figure 1).

234 Interactions between FTO variants and physical activity on obesity-related traits

235 The interaction between the SNP rs9939609 and physical activity levels on adiponectin 236 concentrations was statistically significant $\left(\mathrm{P}_{\text {interaction }}=0.027\right)$, where, among those with 237 lowest levels of physical activity, the adiponectin concentrations were significantly lower in 238 the allele 'A' carriers compared to individuals with 'TT' genotype (P=0.006) (Figure 2).

\section{Associations between GRS and obesity-related traits}

240 The GRS was significantly associated with BMI $(\mathrm{P}=0.002)$, FMI $(\mathrm{P}=0.003)$ and increased

$241 \mathrm{WC}(\mathrm{P}=0.02)$ (Figures 3a, 3b and 3c). However, the interactions between GRS and lifestyle 242 factors on obesity traits were not found statistically significant.

\section{Discussion}

244 To our knowledge, this is the first study that investigated the interaction between FTO SNPs 245 and dietary intake on obesity traits in a Turkish population. This study has identified the 
associations of the FTO SNP rs9939609 and GRS with obesity traits, and also showed that

247 the physical activity level can modify the effect of the minor allele 'A' of the FTO SNP rs9939609 on adiponectin concentrations, a biomarker of metabolic syndrome (Stojanovic et al. 2015). Furthermore, our study has demonstrated that the higher protein intake was associated with higher risk of central obesity among the ' $\mathrm{T}$ ' allele carriers of the FTO SNP rs 10163409 compared to non-carriers. Since Turkish adults have a sedentary lifestyle (WHO, 2018), our findings contribute to the development of effective public health strategies focusing on the prevention and management of central obesity and CVD in Turkish population (IHME, 2017).

This study has shown that the risk allele 'A' of the FTO SNP rs9939609 was significantly associated with higher BMI and FMI, in agreement with the findings from other populations (Frayling et al. 2007; Do et al. 2008; Hertel et al. 2011; Peng et al. 2011; Corella et al. 2012; Li et al. 2012; Muc et al. 2015; Merra et al. 2020). A meta-analysis performed on 177,330 individuals from multiple ethnicities have demonstrated an association between FTO rs9939609 genotype and BMI, suggesting a higher BMI in 'A' allele carriers (effect per allele $=0.30[0.30,0.35] \mathrm{kg} / \mathrm{m}^{2}, \mathrm{P}=3.6^{*} 10^{-107}$ ) (Qi et al. 2014). The reported FTO-related genetic associations with BMI have also been confirmed in a study in the Turkish population

263 (Guclu-Geyik et al. 2016), where the FTO risk allele, 'C', carriers of the SNP rs1421085, 264 which is in a high linkage disequilibrium (LD) $\left(D^{\prime}=0.967, r^{2}=0.85\right)$ with the SNP rs9939609, 265 had significantly increased BMI. Furthermore, parallel to the findings of other studies 266 (Vimaleswaran et al. 2012; De Luis et al. 2016; Saucedo et al. 2017), we have also found that the FTO SNP rs9939609 was significantly associated with higher WC and lower adiponectin concentrations. On the contrary, there were no significant association between SNP rs 10163409 and obesity. This could be explained by the fact that the SNP rs10163409 is not

270 in LD with other FTO variants that have shown significant associations with BMI (Chu et al. $2712013)$. 
Our study has provided evidence for gene-diet interaction in the Turkish population. We have demonstrated that, among those in the highest tertile of dietary protein intake, the risk of increased WC/central obesity was higher for the minor allele, 'T', carriers of the FTO SNP rs 10163409 compared to those with AA genotype. To date, this is the first study analysing gene-diet interactions of the SNP rs10163409, suggesting that high intake of dietary protein might negatively affect WC in genetically susceptible individuals. However, studies investigating other FTO SNPs (rs1558902 and rs9939609) have reported conflicting results (Zhang et al. 2012; de Luis et al. 2015; Merritt et al. 2018). It has been suggested that following a high protein diet can modulate the genetic effect of FTO variants on obesity traits (Zhang et al. 2012; de Luis et al. 2015; Merritt et al. 2018). According to a 2-year weight loss intervention program, carriers of the risk allele 'A' of the FTO rs1558902 had a greater 283 weight loss compared to non-carriers when high protein diets were consumed, whereas a negative genetic effect was found in response to a low-protein intake (Huang et al. 2014). The potential mechanism of FTO variants - protein intake interaction is still unclear, however, the regulation of food intake and appetite could be influenced. It has been found that the risk allele 'A' of the SNP rs9939609 was significantly associated with a greater 288 reduction in food cravings and appetite scores among individuals who consumed high289 protein diet but not in those in the low-protein diet (Huang et al. 2014). Regarding the SNP rs9939609, there were no significant interactions between the FTO variants and any of the dietary components on obesity traits. In agreement with our findings, a study of 11,091 adults

292 from five Europeans countries have found no interactions between the rs9939609 variant and 293 the dietary intake of carbohydrate, glycaemic index, protein or fat on BMI, WC, weight gain and risk of obesity (Vimaleswaran et al. 2012). Furthermore, a meta-analysis of 40 population-based studies reported that the total energy or macronutrient intakes had no effect on the association between the SNP rs9939609 and BMI (Qi et al. 2014). In contrast to our

297 finding, a few large-scale studies demonstrated significant interactions between dietary 
macronutrient intakes and FTO variants in determining BMI (Grau et al. 2009; Sonestedt et

299 al. 2009; Corella et al. 2011; Lappalainen et al. 2012; Ortega-Azorin et al. 2012; Phillips et

300 al. 2012). A cross-sectional study conducted on 4,839 Swedish participants reported an 301 association between the risk allele of the SNP rs9939609 and higher BMI only in individuals 302 with high fat and low carbohydrate consumption (Sonestedt et al. 2009). A similar interaction 303 between the rs9939609 variant and saturated fatty acids (SFA) intake has been detected in 3042,163 individuals from two independent populations of the United States, where individuals 305 homozygous for the risk allele 'AA' had a higher BMI compared to other genotypes, only when the intake of SFA was high (Corella et al. 2011). Furthermore, the FTO SNP rs8050136, in LD with rs9939609, significantly interacted with carbohydrate intake on 308 obesity risk among Asian Indian population (Vimaleswaran et al. 2016).

Regarding genetic interactions with physical activity, a previous study conducted among 200 Turkish adults found that BMI was higher in homozygous risk allele 'A' carriers of the

311 SNP rs9939609 than the homozygote the ' $\mathrm{T}$ ' allele carriers among physically inactive 312 individuals (Kirac et al. 2016). The same interaction but on a biochemical measure of obesity 313 (i.e.: adiponectin level), rather than BMI, was replicated in our study using a larger sample 314 size. We found that, among those with lowest levels of physical activity, the adiponectin 315 concentrations were significantly lower in the carriers of the risk allele 'A' of the FTO 316 rs9939609 than 'TT' homozygotes. Adiponectin is a hormone produced and secreted by 317 adipose tissue and commonly known for its antihyperglycemic, anti-inflammatory, 318 antiatherogenic, and cardioprotective effects (Richard et al. 2020; Esmaili et al. 2020; Lee 319 and Shao 2014). Studies have reported a strong correlation between the dysregulation of 320 adipokine production and the onset of several metabolic abnormalities including CVD and 321 cancer (Avogaro and de Kreutzenberg 2005; De Pergola and Silvestris 2013; Xiang et al. 322 2020). The positive correlation between adiponectin levels and physical activity has been 323 demonstrated in several studies (St-Pierre et al. 2006; Jurimae et al. 2010; Sirico et al. 2018), 
where higher levels of physical activity have been shown to reduce adiposity which decreases

325 the production of insulin and leptin, and increases adiponectin production (Nurnazahiah et al. 2016). Indeed, it has been reported that serum concentrations of adiponectin are inversely related to BMI, visceral body fat and blood concentrations of glucose, insulin, and triglycerides (De Rosa et al. 2013; Frithioff-Bojsoe et al. 2020). An intervention study conducted in 400 obese women showed that a weight reduction program resulted in a 330 significant increase in adiponectin levels (Mavri et al. 2011). Given that this is the first study 331 to report an interaction between FTO variant and physical activity on adiponectin concentrations, the findings need to be replicated in a larger Turkish cohort.

The main strengths of this study include the use of a biochemical marker of obesity (i.e., adiponectin) and a well-characterised population. Nevertheless, there are some limitations 335 which include the small sample size and the use of self-reported measurements in the assessment of dietary intake and physical activity. However, this study has still confirmed the associations between FTO SNP rs9939609 and obesity traits which were also reported in previous studies (Frayling et al. 2007; Hertel et al. 2011; Peng et al. 2011; Corella et al. 2012; Li et al. 2012; Merra et al. 2020; Schlauch et al. 2020). Given that obesity is a multifactorial 340 condition, several genetic factors and lifestyle behaviours provide a predisposition to obesity; 341 even though we have focused on the two important lifestyle factors, diet and physical activity, 342 only two genetic variants were examined. However, to date, the FTO gene has been shown 343 to be the strongest susceptibility gene for common obesity (Frayling et al. 2007; Scuteri et 344 al. 2007; Speliotes et al. 2010; Loos an Yeo 2014). Furthermore, the cross-sectional design 345 of this study limits the proof of causality. Even though our analysis was adjusted for several 346 confounders, we cannot rule out the residual confounding caused by unknown factors. 347 Therefore, the observed interactions needed to be confirmed in further studies with larger 348 sample sizes. 
In summary, this study has confirmed the associations between the risk allele 'A' of the FTO rs9939609 and GRS, with obesity related traits including BMI and FMI in this Turkish population. Our study suggests that the impact of the FTO polymorphisms, rs10163409 and rs9939609, on obesity among Turkish adults might be affected by dietary protein intake and physical activity levels, respectively, suggesting that increased consumption of protein-rich foods and sedentary lifestyle could possibly increase the genetic risk ofc central obesity. Our results provide significant public health implications, given that the rising prevalence of central obesity is a major public health problem in Turkey (Pekcan et al. 2017; WHO, 2018). Further studies with large sample size and objective measures of environmental factors are required to provide a better understanding of how these variants interact with lifestyle factors to develop effective prevention and treatment strategies for obesity.

361 Acknowledgments: We thank all study participants for their cooperation. Dr Karani S 362 Vimaleswaran acknowledges support from the British Nutrition Foundation, and also from 363 the Ministry of Higher Education of Saudi Arabia for the scholarship given to Sooad 364 Alsulami. Dr Buyuktuncer acknowledges the Scientific and Technological Research Council 365 of Turkey (TUBITAK) and Council of Higher Education of Turkey for the scholarship given 366 to Kubra Isgin-Atici. The preliminary results of the study were presented at the Nutrition 367 Society Spring Conference in 1-2 April 2019.

368 Disclosure Statement: The authors report no conflict of interest.

369 Funding: This work was supported by the Scientific and Technological Research Council of 370 Turkey (TUBITAK) under Grant 216S272. 


\section{References}

Abete I, Navas-Carretero S, Zulet MA, Martinez JA. 2020. Genetic Regulation of Energy Homeostasis: Obesity Implications. In: Principles of Nutrigenetics and Nutrigenomics, Ed. Caterina RDE, Martinez JA, Kohlmeier M: Academic Press. p. 175-180.

Avogaro A, de Kreutzenberg SV. 2005. Mechanisms of endothelial dysfunction in obesity. Clin Chim Acta. 360(1-2):9-26.

Babenko V, Babenko R, Gamieldien J, Markel A. 2019. FTO haplotyping underlines high obesity risk for European populations. BMC Med Genomics. 13;12(Suppl 2):46.

Castillo JJ, Orlando RA, Garver WS. 2017. Gene-nutrient interactions and susceptibility to human obesity. Genes Nutr. 12:29.

Chu AY, Workalemahu T, Paynter NP, Rose LM, Giulianini F, Tanaka T, Ngwa JS, Qi Q, Curhan GC, Rimm EB et al. 2013. Novel locus including FGF21 is associated with dietary macronutrient intake. Hum Mol Genet. 22(9):1895-1902.

Chen J, Du B. 2019. Novel positioning from obesity to cancer: FTO, an m(6)A RNA demethylase, regulates tumour progression. J Cancer Res Clin Oncol.145(1):19-29.

Clifton IJ, McDonough MA, Ehrismann D, Kershaw NJ, Granatino N, Schofield CJ. 2006. Structural studies on 2-oxoglutarate oxygenases and related double-stranded $\beta$ helix fold proteins. J Inorg Biochem 100(4):644-669.

Corella D, Arnett DK, Tucker KL, Kabagambe EK, Tsai M, Parnell LD, Lai CQ, Lee YC, Warodomwichit D, Hopkins PN et al. 2011. A high intake of saturated fatty acids strengthens the association between the fat mass and obesity-associated gene and BMI. J Nutr. 141(12):2219-2225.

Corella D, Carrasco P, Sorli JV, Coltell O, Ortega-Azorin C, Guillen M, Gonzalez JI, Saiz C, Estruch R, Ordovas JM. 2012. Education modulates the association of the FTO 
rs9939609 polymorphism with body mass index and obesity risk in the Mediterranean population. Nutr Metab Cardiovasc Dis. 22(8):651-658.

Dahlman I, Rydén M. 2020. Gene-Environment Interaction and Individual Susceptibility to Metabolic Disorders. In: Beyond Our Genes. Ed.Teperino R, Castillo JJ, Orlando RA, Garver WS.Springer, Switzerland.p.81-94

De Luis DA, Aller R, Izaola O, Primo D, Romero E. 2016. Association of the rs9939609 gene variant in FTO with insulin resistance, cardiovascular risk factor and serum adipokine levels in obese patients. Nutr Hosp. 33(5):573.

De Luis DA, Aller R, Izaola O, Primo D, Urdiales S, Romero E. 2015. Effects of a HighProtein/Low-Carbohydrate Diet versus a Standard Hypocaloric Diet on Weight and Cardiovascular Risk Factors: Role of a Genetic Variation in the rs9939609 FTO Gene Variant. J Nutrigenet Nutrigenomics. 8(3):128-136.

De Pergola G, Silvestris F. 2013. Obesity as a major risk factor for cancer. J Obes. 2013:291546.

De Rosa A, Monaco ML, Capasso M, Forestieri P, Pilone V, Nardelli C, Buono P, Daniele A. 2013. Adiponectin oligomers as potential indicators of adipose tissue improvement in obese subjects. Eur J Endocrinol. 169(1):37-43.

Do R, Bailey SD, Desbiens K, Belisle A, Montpetit A, Bouchard C, Perusse L, Vohl MC, Engert JC. 2008. Genetic variants of FTO influence adiposity, insulin sensitivity, leptin levels, and resting metabolic rate in the Quebec Family Study. Diabetes. 57(4):11471150.

Esmaili S, Hemmati M, Karamian M. 2020. Physiological role of adiponectin in different tissues: a review. Arc Physiol Biochem. 126(1):67-73.

Fonseca ACPD, Marchesini B, Zembrzuski VM, Voigt DD, Ramos VG, Carneiro JRI, Nogueira Neto JF, Cabello GMK, Cabello PH. 2020. Genetic variants in the fat mass and 
obesity-associated (FTO) gene confer risk for extreme obesity and modulate adiposity in a Brazilian population. Genet Mol Biol. 6;43(1):e20180264.

Forse RA, Betancourt-Garcia MM, Kissee MC. 2020. Epidemiology and Discrimination in Obesity. In: The ASMBS Textbook of Bariatric Surgery. Ed.Nguyen N, Brethauer S, Morton J, Ponce J, Rosenthal R. Springer, New York, NY.p.3-14.

Franks PW, McCarthy MI. 2016. Exposing the exposures responsible for type 2 diabetes and obesity. Science. 354(6308):69-73.

Frayling TM, Timpson NJ, Weedon MN, Zeggini E, Freathy RM, Lindgren CM, Perry JR, Elliott KS, Lango H, Rayner NW et al. 2007. A common variant in the FTO gene is associated with body mass index and predisposes to childhood and adult obesity. Science. 316(5826):889-894.

Frese EM, Fick A, Sadowsky HS. 2011. Blood pressure measurement guidelines for physical therapists. Cardiopulm Phys Ther J. 22(2):5-12.

Frithioff-Bøjsøe C, Lund MAV, Lausten-Thomsen U, Hedley PL, Pedersen O, Christiansen M, Baker JL, Hansen T, Holm J-C. 2020. Leptin, adiponectin, and their ratio as markers of insulin resistance and cardiometabolic risk in childhood obesity. Pediatr Diabetes. 21(2):194-202.

Grau K, Hansen T, Holst C, Astrup A, Saris WH, Arner P, Rossner S, Macdonald I, Polak J, Oppert JM et al. 2009. Macronutrient-specific effect of FTO rs9939609 in response to a 10-week randomized hypo-energetic diet among obese Europeans. Int J Obes (Lond). 33(11):1227-1234.

Guclu-Geyik F, Onat A, Yuzbasiogullari AB, Coban N, Can G, Lehtimaki T, ErginelUnaltuna N. 2016. Risk of obesity and metabolic syndrome associated with FTO gene variants discloses clinically relevant gender difference among Turks. Mol Biol Rep. 43(6):485-494. 
Hertel JK, Johansson S, Sonestedt E, Jonsson A, Lie RT, Platou CG, Nilsson PM, Rukh G, Midthjell K, Hveem K et al. 2011. FTO, type 2 diabetes, and weight gain throughout adult life: a meta-analysis of 41,504 subjects from the Scandinavian HUNT, MDC, and MPP studies. Diabetes. 60(5):1637-1644.

Huang T, Qi Q, Li Y, Hu FB, Bray GA, Sacks FM, Williamson DA, Qi L. 2014. FTO genotype, dietary protein, and change in appetite: the Preventing Overweight Using Novel Dietary Strategies trial. Am J Clin Nutr. 99(5):1126-1130.

IHME: measuring what matters 2017 [Internet]. The Institute for Health Metrics and Evaluation; [cited 2020 July 1]. Available from: http://www.healthdata.org/turkey Jurimae J, Kums T, Jurimae T. 2010. Plasma adiponectin concentration is associated with the average accelerometer daily steps counts in healthy elderly females. Eur J Appl Physiol. 109(5):823-828.

Kirac D, Kasimay Cakir O, Avcilar T, Deyneli O, Kurtel H, Yazici D, Kaspar EC, Celik N, Guney AI. 2016. Effects of MC4R, FTO, and NMB gene variants to obesity, physical activity, and eating behavior phenotypes. IUBMB Life. 68(10):806-816.

Lappalainen T, Lindstrom J, Paananen J, Eriksson JG, Karhunen L, Tuomilehto J, Uusitupa M. 2012. Association of the fat mass and obesity-associated (FTO) gene variant (rs9939609) with dietary intake in the Finnish Diabetes Prevention Study. Br J Nutr. 108(10):1859-1865.

Lee B, Shao J. 2014. Adiponectin and energy homeostasis. Rev Endocr Metab Disord. 15(2):149-156.

Li H, Kilpeläinen TO, Liu C, Zhu J, Liu Y, Hu C, Yang Z, Zhang W, Bao W, Cha S et al. 2012. Association of genetic variation in FTO with risk of obesity and type 2 diabetes with data from 96,551 East and South Asians. Diabetologia. 55(4):981-995. 
Loos RJF, Yeo GSH. 2014. The bigger picture of FTO - the first GWAS-identified obesity gene. Nat Rev Endocrinol. 10(1):51-61.

Mavri A, Poredos P, Suran D, Gaborit B, Juhan-Vague I, Poredos P. 2011. Effect of dietinduced weight loss on endothelial dysfunction: early improvement after the first week of dieting. Heart Vessels. 26(1):31-38.

Merra G, Gualtieri P, Cioccoloni G, Falco S, Bigioni G, Tarsitano MG, Capacci A, Piccioni A, Costacurta M, Franceschi F et al. 2020. FTO rs9939609 influence on adipose tissue localization in the Italian population. Eur Rev Med Pharmacol Sci. 24(6):32233235.

Merritt DC, Jamnik J, El-Sohemy A. 2018. FTO genotype, dietary protein intake, and body weight in a multiethnic population of young adults: a cross-sectional study. Genes Nutr. 13:4.

Milagro FI, Moreno-Aliaga MJ, Martínez JA. 2020. Nutrients, Obesity and Gene Expression. In Principles of Nutrigenetics and Nutrigenomics. Ed. Caterina RDE, Martinez JA, Kohlmeier M. Academic Press. p. 431-440.

Muc M, Padez C, Manco LJAJoHB. 2015. Influence of physical activity on the association between the FTO variant rs9939609 and adiposity in young adults. 27(5):734-738.

Nurnazahiah A, Lua PL, Shahril MR. 2016. Adiponectin, Leptin and Objectively Measured Physical Activity in Adults: A Narrative Review. Malays J Med Sci. 23(6):724.

OECD. Obesity Update- 2017 [Internet]. Organisation for Economic Cooperation and Development; [cited 2020 July 2]. Available from: http://www.oecd.org/health/obesityupdate.htm. 
Onat A. 2001. Risk factors and cardiovascular disease in Turkey. Atherosclerosis. 156(1):1-10.

Onat A, Can G. 2014. Enhanced proinflammatory state and autoimmune activation: a breakthrough to understanding chronic diseases. Curr Pharm Des. 20(4):575-584.

Ortega-Azorin C, Sorli JV, Asensio EM, Coltell O, Martinez-Gonzalez MA, SalasSalvado J, Covas MI, Aros F, Lapetra J, Serra-Majem L et al. 2012. Associations of the FTO rs9939609 and the MC4R rs17782313 polymorphisms with type 2 diabetes are modulated by diet, being higher when adherence to the Mediterranean diet pattern is low. Cardiovasc Diabetol. 11:137.

Pekcan AG, Samur G, Dikmen D, Kızıl M, Rakıcığlu N, Yıldız EA, Özel HG, Mercanlıgil SM, Ersoy G, Karaağaoğlu N. et al. 2018. Population based study of obesity in Turkey: results of the Turkey Nutrition and Health Survey (TNHS)-2010. Prog. Nutr. 19(3):248-56.

Peltz G, Aguirre MT, Sanderson M, Fadden MK. 2010. The role of fat mass index in determining obesity. Am J Hum Biol. 22(5):639-647.

Peng S, Zhu Y, Xu F, Ren X, Li X, Lai M. 2011. FTO gene polymorphisms and obesity risk: a meta-analysis. BMC medicine. 9:71-71.

Phillips CM, Kesse-Guyot E, McManus R, Hercberg S, Lairon D, Planells R, Roche HM. 2012. High dietary saturated fat intake accentuates obesity risk associated with the fat mass and obesity-associated gene in adults. J Nutr. 142(5):824-831.

Pigeyre M, Yazdi FT, Kaur Y, Meyre D. 2016. Recent progress in genetics, epigenetics and metagenomics unveils the pathophysiology of human obesity. Clin Sci (Lond). 130(12):943-986. 
Qi Q, Kilpeläinen TO, Downer MK, Tanaka T, Smith CE, Sluijs I, Sonestedt E, Chu AY, Renström F, Lin X et al. 2014. FTO genetic variants, dietary intake and body mass index: insights from 177,330 individuals. Hum Mol Genet. 23(25):6961-6972.

Richard AJ, White U, Elks CM, Stephens JM. Adipose Tissue: Physiology to Metabolic Dysfunction. 2020. Endotext; [cited 2020 July 2]. Available from: https://www.ncbi.nlm.nih.gov/books/NBK555602/.

Saber-Ayad M, Manzoor S, Radwan H, Hammoudeh S, Wardeh R, Ashraf A, Jabbar H, Hamoudi R. 2019. The FTO Genetic Variants Are Associated With Dietary Intake and Body Mass Index Amongst Emirati Population. PLoS One. 17;14(10):e0223808. doi: 10.1371/journal.pone.0223808.

Saglam M, Arikan H, Savci S, Inal-Ince D, Bosnak-Guclu M, Karabulut E, Tokgozoglu L. 2010. International physical activity questionnaire: reliability and validity of the Turkish version. Percept Mot Skills. 111(1):278-284.

Saucedo R, Valencia J, Gutierrez C, Basurto L, Hernandez M, Puello E, Rico G, Vega G, Zarate A. 2017. Gene variants in the FTO gene are associated with adiponectin and TNFalpha levels in gestational diabetes mellitus. Diabetol Metabol Syndr. 9:32-32.

Sirico F, Bianco A, D'Alicandro G, Castaldo C, Montagnani S, Spera R, Di Meglio F, Nurzynska D. 2018. Effects of Physical Exercise on Adiponectin, Leptin, and Inflammatory Markers in Childhood Obesity: Systematic Review and Meta-Analysis. Child Obes. 14(4):207-217.

Schlauch KA, Read RW, Lombardi VC, Elhanan G, Metcalf WJ, Slonim AD, Grzymski JJ. 2020. A Comprehensive Genome-Wide and Phenome-Wide Examination of BMI and Obesity in a Northern Nevadan Cohort. G3: Genes Genom Genet. 10(2):645-664. 
Scuteri A, Sanna S, Chen WM, Uda M, Albai G, Strait J, Najjar S, Nagaraja R, Orru M, Usala $\mathrm{G}$ et al. 2007. Genome-wide association scan shows genetic variants in the FTO gene are associated with obesity-related traits. PLoS Genet. 3(7):e115.

Sonestedt E, Roos C, Gullberg B, Ericson U, Wirfalt E, Orho-Melander M. 2009. Fat and carbohydrate intake modify the association between genetic variation in the FTO genotype and obesity. Am J Clin Nutr. 90(5):1418-1425.

Sonmez A, Bayram F, Barcin C, Ozsan M, Kaya A, Gedik V. 2013. Waist circumference cutoff points to predict obesity, metabolic syndrome, and cardiovascular risk in Turkish adults. Int J Endocrinol. 2013:767202.

Speliotes EK, Willer CJ, Berndt SI, Monda KL, Thorleifsson G, Jackson AU, Lango Allen H, Lindgren CM, Luan J, Magi R et al. 2010. Association analyses of 249,796 individuals reveal 18 new loci associated with body mass index. Nat Genet. 42(11):937948.

St-Pierre DH, Faraj M, Karelis AD, Conus F, Henry JF, St-Onge M, Tremblay-Lebeau A, Cianflone K, Rabasa-Lhoret R. 2006. Lifestyle behaviours and components of energy balance as independent predictors of ghrelin and adiponectin in young non-obese women. Diabetes Metab. 32(2):131-139.

Stojanovic S, Ilic MD, Ilic S, Petrovic D, Djukic S. 2015. The significance of adiponectin as a biomarker in metabolic syndrome and/or coronary artery disease. Vojnosanit Pregl. 72(9):779-784.

Vimaleswaran KS. 2017. Gene-nutrient interactions on metabolic diseases: Findings from the GeNuIne Collaboration. Nutr Bull. 42(1):80-86.

Vimaleswaran KS, Angquist L, Hansen RD, van der AD, Bouatia-Naji N, Holst C, Tjonneland A, Overvad K, Jakobsen MU, Boeing H et al. 2012. Association between 
FTO variant and change in body weight and its interaction with dietary factors: the DiOGenes study. Obesity (Silver Spring). 20(8):1669-1674.

Vimaleswaran KS, Bodhini D, Lakshmipriya N, Ramya K, Anjana RM, Sudha V, Lovegrove JA, Kinra S, Mohan V, Radha V. 2016. Interaction between FTO gene variants and lifestyle factors on metabolic traits in an Asian Indian population. Nutr Metab (Lond). $13: 39$.

Wang D, Wu Z, Zhou J, Zhang X. 2020. Rs9939609 polymorphism of the fat mass and obesity-associated (FTO) gene and metabolic syndrome susceptibility in the Chinese population: a meta-analysis. Endocrine. doi: 10.1007/s12020-020-02280-x. Online ahead of print.

WHO. 2005. Preventing Chronic Diseases: a Vital Investment: Geneva, World Health Organization. [Internet]. World Health Organization; [cited 2020 July 1]. Available from: https://www.who.int/chp/chronic_disease_report/en/].

WHO. 2016. Turkish Healthy Nutrition and Active Life Programme 2010-2014 and related initiatives [Internet]. World Health Organisation; [cited 2020 July 2]. Available from: $\quad$ https://www.euro.who.int/en/countries/turkey/publications/turkish-healthynutrition-and-active-life-programme-20102014-and-related-initiatives-2016.

WHO. 2020. Body mass index-BMI. [Internet]. World Health Organisation; [cited 2020 July 2]. Available from: http://www.euro.who.int/en/health-topics/diseaseprevention/nutrition/a-healthy-lifestyle/body-mass-index-bmil.

WHO. 2018. National Household Health Survey - Prevalence of Noncommunicable Disease Risk Factors in Turkey 2017 2018. [Internet]. World Health Organisation; [cited 2020 July 1]. Available from: http://www.euro.who.int/en/countries/turkey/publications/national-household-healthsurvey-prevalence-of-noncommunicable-disease-risk-factors-in-turkey-2017-2018. 
WHO. 2011. Waist Circumference and Waist-Hip Ratio. [Internet]. World Health Organisation Report of a WHO expert consultation, Geneva, 8-11 December 2008; [cited 2020 July 1]. Available from: https://www.who.int/nutrition/publications/obesity/WHO_report_waistcircumference_a nd_waisthip_ratio/en/.

Xiang Y, Zhou W, Duan X, Fan Z, Wang S, Liu S, Liu L, Wang F, Yu L, Zhou F et al. 2020. Metabolic Syndrome, and Particularly the Hypertriglyceridemic-Waist Phenotype, Increases Breast Cancer Risk, and Adiponectin Is a Potential Mechanism: A CaseControl Study in Chinese Women. Front Endocrinol. 10(905).

Zhang X, Qi Q, Zhang C, Smith SR, Hu FB, Sacks FM, Bray GA, Qi L. 2012. FTO genotype and 2-year change in body composition and fat distribution in response to weight-loss diets: the POUNDS LOST Trial. Diabetes. 61(11):3005-3011.

\section{Figure Captions}

Figure 1. Interactions of the FTO rs10163409 with tertiles of protein intake (g) on increased WC. WC, Waist Circumference. Black bars implicate the ' $\mathrm{T}$ ' allele carriers (TA+TT). FTO SNP rs10163409 showed a significant interaction with protein intake (g) on the risk of increased $\mathrm{WC}\left(\mathrm{P}_{\text {interaction }}=0.044\right)$. Among those in the highest tertile of protein intake (mean $\pm \mathrm{SD}$ : $138 \pm 38 \mathrm{~g} /$ day), the minor ' $\mathrm{T}$ ' allele carriers of the SNP rs10163409 had a significantly higher risk of increased WC [OR= 3.3 (95\% CI: 1.149 9.478), $\mathrm{p}=0.027]$ than those carrying 'AA' genotype. *Odds ratio adjusted for age, gender, hypertension, cardiovascular diseases, total energy intake and obesity status 
Figure 2. Interactions between FTO rs9939609 variant and physical activity on adiponectin levels. White bars indicate carriers of ' $\mathrm{TT}$ ' genotype. Black bars implicate the risk allele, 'A', carriers (AT +AA). The regression model was adjusted for age, gender hypertension, cardiovascular diseases and obesity status. There was a significant interaction between the FTO SNP rs9939609 and physical activity on adiponectin levels $\left(\mathrm{P}_{\text {interaction }}=0.027\right)$, where, among those with low physical activity levels, carriers of the 'A' allele had significantly lower adiponectin levels compared to those with 'TT' genotype $(\mathrm{p}=0.006)$.

Figure 3. Association between the genetic risk score of the FTO SNPs, rs9939609 and rs10163409s and anthropometric measures of obesity.

BMI, Body Mass Index; FMI, Fat Mass Index; WC, Waist Circumference. White bars: means of individuals with genetic risk score (GRS) of $<2$ risk alleles. Black bars: means of individuals with GRS of $\geq 2$ or more risk alleles. The GRS was significantly associated with BMI (3a), FMI (3b) and WC (3c). Figure 3a; carriers of $\geq 2$ or more risk alleles of the FTO variants (rs9939609 and rs10163409) had higher BMI (P=0.002) compared to individuals carrying $<2$ risk alleles. Figure $3 b$; carriers of $\geq 2$ or more risk alleles of the FTO variants (rs9939609 and rs10163409) had higher FMI ( $\mathrm{P}=0.003)$ compared to individuals carrying $<2$ risk alleles. Figure $3 \mathrm{c}$; carriers of $\geq 2$ or more risk alleles of the FTO variants (rs9939609 and rs10163409) had higher WC $(\mathrm{P}=0.020)$ compared to individuals carrying $<2$ risk alleles. $\mathrm{P}$ values were obtained from linear regression analysis and adjusted for age, gender, hypertension, cardiovascular diseases and obesity status. 